\title{
The interaction of ultraviolet light with Arctic sea ice during SHEBA
}

\author{
Donald K. PEROVICH \\ US Army Cold Regions Research and Engineering Laboratory, 72 Lyme Road, Hanover, NH 03755-1290, USA \\ E-mail: donald.k.perovich@erdc.usace.army.mil
}

\begin{abstract}
The reflection, absorption and transmission of ultraviolet light by a sea-ice cover strongly impacts primary productivity, higher trophic components of the food web, and humans. Measurements of the incident irradiance at 305, 320, 340 and $380 \mathrm{~nm}$ and of the photosynthetically active radiation were made from April through September 1998 as part of the SHEBA (Surface Heat Budget of the Arctic Ocean program) field experiment in the Arctic Ocean. In addition, observations of snow depth and ice thickness were made at more than 100 sites encompassing a comprehensive range of conditions. The thickness observations were combined with a radiative transfer model to compute a time series of the ultraviolet light transmitted by the ice cover from April through September. Peak values of incident ultraviolet irradiance occurred in mid-June. Peak transmittance was later in the summer at the end of the melt season when the snow cover had completely melted, the ice had thinned and pond coverage was extensive. The fraction of the incident ultraviolet irradiance transmitted through the ice increased by several orders of magnitude as the melt season progressed. Ultraviolet transmittance was approximately a factor of ten greater for melt ponds than bare ice. Climate change has the potential to alter the amplitude and timing of the annual albedo cycle of sea ice. If the onset of melt occurs at increasingly earlier dates, ultraviolet transmittance will be significantly enhanced, with potentially deleterious biological impacts.
\end{abstract}

\section{INTRODUCTION}

Reduced levels of stratospheric ozone continue to result in enhanced surface amounts of ultraviolet radiation (UVR: $280-400 \mathrm{~nm}$ ) in the Arctic and Antarctic. The ultraviolet portion of the spectrum is divided into two segments: UV-B $(280-320 \mathrm{~nm})$ and UV-A (320-400 nm). In the Arctic, much of the region affected by this enhanced ultraviolet is covered by sea ice and is the home of a rich microbial community (Palmisano and Sullivan, 1983; Cota and others, 1990, 1991; Horner and others, 1992) which fuels higher trophic levels and significantly contributes to the biogeochemical cycle in polar seas (e.g. Gosselin and others 1997; Thomas and Dieckmann, 2002). A combination of sufficient radiative energy, nutrient supply from below, and tolerable temperatures creates a relatively sheltered environment where a shade-adapted algal community reaches visible concentrations. The maximum concentration of this biomass is located near the bottom of the ice, where light that has propagated through the entire ice column is partially absorbed by high concentrations of algal pigments. Ultraviolet light has been shown to cause ecological damage in the open ocean (Smith and others, 1992; Prézelin and others, 1994, 1998) and in under-ice communities (Prézelin and others, 1998; McMinn and others, 1999). In addition, phytoplankton (Heibling and others, 1994) and algae (Karentz, 1994) are strong absorbers of ultraviolet light.

Assessing the biological impact of enhanced ultraviolet radiation on this community is considerably complicated by the spatial and temporal variability of the sea-ice cover. Levels of ultraviolet light above, within and beneath a seaice cover have been shown to be strongly influenced by the surface conditions, scattering and absorption in the snow and sea ice, the snow depth, the ice thickness and the amount of impurities present (Grenfell, 1983, 1991; Trodahl and Buckley, 1990; Perovich, 1993, 2001; Light and others, $2003 a, b)$. Recent climate trends in the Arctic suggest an earlier onset of ice melt, longer melt seasons and a transition to thinner ice. These trends have the potential to modulate the amplitude and timing of the annual albedo cycle of sea ice (Perovich and others, 2002) and to impact the distribution of the incident ultraviolet radiation.

A network of stations monitoring the incident ultraviolet radiation at Barrow, Alaska, USA, and Palmer Station, Antarctica, has been operating since 1987. However, observations of the incident ultraviolet irradiance on the sea ice in the Arctic Ocean are sparse. Also lacking is information on the partitioning of the incident ultraviolet light between reflection to the atmosphere, absorption in the snow and ice, and transmission to the ocean.

In this paper, we first examine the seasonal evolution of the incident ultraviolet irradiance using observations made during the SHEBA (Surface Heat Budget of the Arctic Ocean program) field experiment (Perovich and others, 1999; Uttal and others, 2002). The measurements were made in the Beaufort Sea from February to September 1998. The temporal evolution and spatial variability of the transmitted ultraviolet irradiance is then explored by coupling a radiative transfer model (Perovich, 1993, 2001) with observations of the ice morphological conditions (Perovich and others, 2002).

\section{INSTRUMENTS AND METHODS}

The SHEBA field program was a year-long field experiment studying the surface heat budget of the Arctic Ocean (Perovich and others, 1999; Uttal and others, 2000). Measurements included a comprehensive time series of solar and longwave radiation, air temperature, wind speed, 


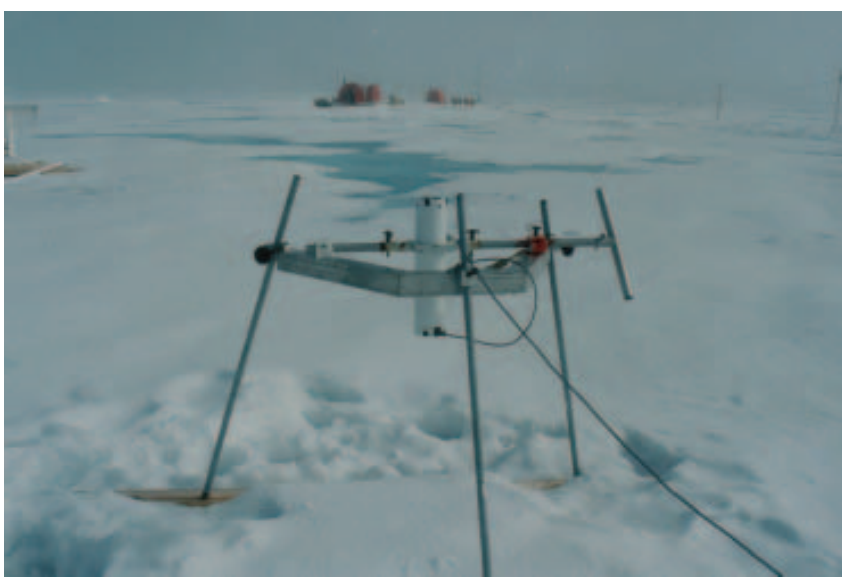

Fig. 1. Photograph of Biospherical Instruments PUV-500 installed at Ice Station SHEBA on 22 June 1998.

cloud properties and the sea-ice mass balance. As part of this effort, a Biospherical Instruments PUV-500 ultraviolet radiometer was installed at Ice Station SHEBA to measure the incident irradiance at 305, 320, 340 and $380 \mathrm{~nm}$. This instrument is used for the United States National Science Foundation ultraviolet monitoring network (Booth and others, 1995) and is designed specifically for accurate observations of the incident ultraviolet irradiance. The instrument was calibrated before being sent into the field. Incident irradiances were automatically recorded at $5 \mathrm{~min}$ intervals from 20 February to 4 September 1998. The instrument was installed in an open area, with a clear view of the sky, near the central SHEBA meteorological station (Fig. 1). The instrument was visited at least once a day to clean the cosine collector of any accumulated snow, ice or water. Small adjustments $\left(<1^{\circ}\right)$ were made to keep the instrument level. Data-logger problems resulted in a few short ( $<1$ day) gaps in the record.

No direct observations were made of ultraviolet transmission through the ice. However, ultraviolet transmittance was computed by using SHEBA observations of snow depth, ice thickness, melt-pond depth and ice morphology as input parameters to a two-dimensional radiative transfer model (Perovich, 1990, 1993). A year-long time series of ice mass balance was measured at more than 100 sites using a combination of ablation stakes and thickness gauges (Perovich and others, 2003). These sites were selected to encompass the full range of first-year and multiyear ice conditions including undeformed ice, ridged ice and ponded ice. In addition, surveys of snow depth and ice thicknesses were occasionally made during the spring and summer (Eicken and others, 2001).

The SHEBA ice morphology observations were used to specify the model input parameters for the transmittance calculations. March-September consisted of three periods: pre-melt, melt and freeze-up. For calculations prior to the onset of melt, the ice was assumed to consist of three layers: (a) a dry snow layer of observed depth $H_{\mathrm{s}}$ (b) an upper drained ice layer equal to the freeboard $\left(0.1 H_{\mathrm{i}}\right)$, with $(\mathrm{c})$ cold ice below $\left(0.9 H_{\mathrm{i}}\right)$. As the melt season began, the dry snow became melting snow, and the cold ice changed to melting ice. Once the snow melted, there was bare ice and ponded ice. Bare melting ice consisted of: (a) a surface scattering layer whose thickness was measured, (b) a drained ice layer

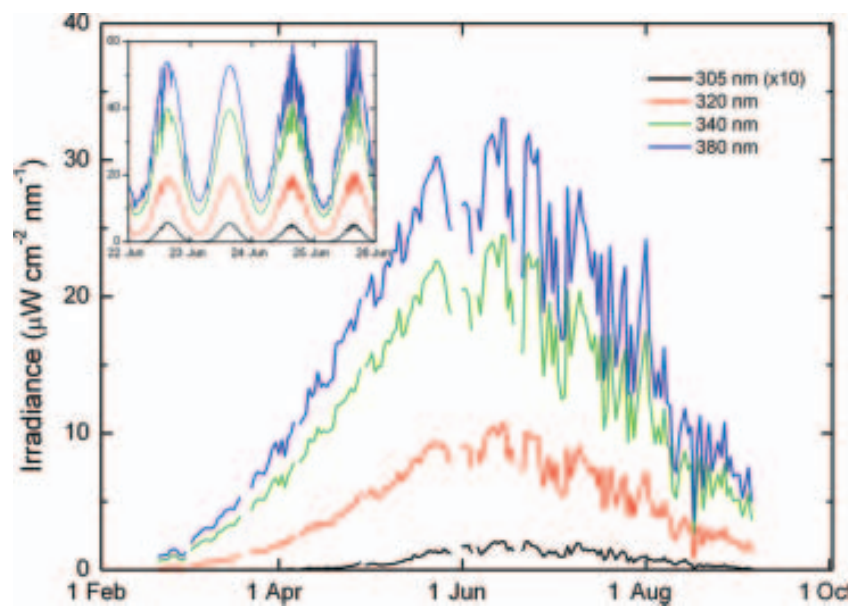

Fig. 2. Time series of daily averages of incident ultraviolet irradiance at 305, 320, 340 and $380 \mathrm{~nm}$. Plotted in the insert are values measured every $5 \mathrm{~min}$ from 22 June to 26 June. Note that all values at $305 \mathrm{~nm}$ have been multiplied by 10 for better display on the graph.

whose thickness was equal to the ice freeboard $\left(0.1 H_{\mathrm{i}}\right)$ and (c) melting ice $\left(0.9 H_{\mathrm{i}}\right)$. Ponded ice consisted of clear water of observed depth $H_{p}$, with $1.0 H_{i}$ of melting ice underneath. The ice physical description was translated to ice optical properties following Grenfell and Maykut (1977) and Perovich (1993). The model was used to compute two quantities: (a) the transmittance, the fraction of the incident irradiance transmitted, and (b) the transmitted irradiance, the amount of ultraviolet reaching the ice bottom. Note that the transmitted irradiance is simply the transmittance multiplied by the incident ultraviolet irradiance.

\section{RESULTS AND DISCUSSION} Incident ultraviolet irradiance

Daily averages of incident ultraviolet irradiance are plotted in Figure 2. The seasonal cycle of incident ultraviolet due to changing solar zenith angle is evident. Peak values occurred on 14 June, a week before the summer solstice, due to increasing clouds and water vapor in the atmosphere. In winter and spring, day-to-day variations in incident irradiance were a modest $10-20 \%$. In summer these fluctuations grew to $20-50 \%$ due to the overall increase in clouds and the greater variability in cloud conditions.

The insert in Figure 2 displays the diurnal cycle near the summer solstice from 22 to 26 June. Ice Station SHEBA was at $78^{\circ} \mathrm{N}$, so the solar elevation angle was approximately $35^{\circ}$ at noon and $11^{\circ}$ at midnight. This represents an increase of atmospheric path length of a factor of three. The noon to midnight diurnal decrease in incident ultraviolet irradiance at the surface was more than a factor of 50 at $305 \mathrm{~nm}$, where absorption by the atmosphere is greatest. It was smaller, but still significant, at longer wavelengths: roughly a factor of 7 at $320 \mathrm{~nm}$ and a factor of 7 at 340 and $380 \mathrm{~nm}$. Skies were clear on 22 and 23 June, and the diurnal cycle was a smooth curve. Partly cloudy conditions were present on 24 and 25 June, resulting in high-frequency incident fluctuations of $40 \%$ that were superposed on the diurnal cycle.

Spectral profiles of incident irradiance on the first of the month from April through August are plotted in Figure 3. 


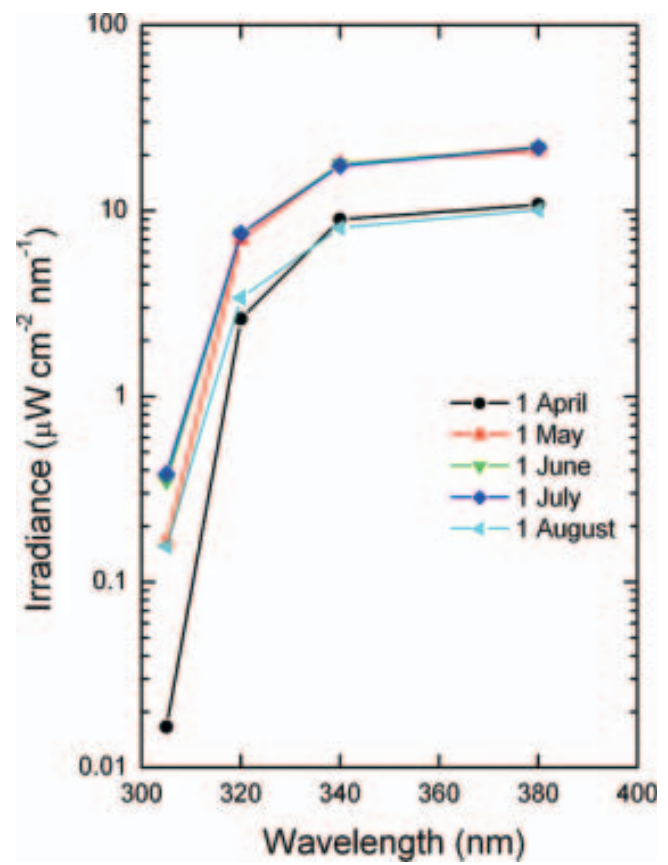

Fig. 3. Spectral profiles of incident ultraviolet irradiance on 1 April, 1 May, 1 June, 1 July and 1 August.

A strong spectral dependence is evident in this figure. In April the incident irradiance at $305 \mathrm{~nm}$ is nearly two orders of magnitude smaller than at $380 \mathrm{~nm}$. The month-to-month variability is greatest at $305 \mathrm{~nm}$ and decreases with increasing wavelength. At $305 \mathrm{~nm}$ the range of the incident irradiance from April to July is a factor of 22 compared to a factor of 3 at $320 \mathrm{~nm}$ and a factor of 2 at 340 and $380 \mathrm{~nm}$.

\section{Time series of calculated transmitted ultraviolet irradiance}

From a primary productivity perspective, the amount of ultraviolet light reaching the underside of the ice is a key issue. While there were no direct measurements of ultraviolet transmission during SHEBA, we were able to couple ice morphology observations with a radiative transfer model (Perovich, 1993) to investigate the temporal evolution of light transmission. The key morphological parameters for light transmittance are snow depth, surface scattering layer thickness, pond depth and ice thickness (Grenfell and Maykut, 1977). The two principal summer ice types were investigated: unponded and ponded multiyear ice. Figure $4 \mathrm{a}$ and $b$ display the seasonal evolution of snow depth, ice thickness and pond depth for representative unponded and ponded cases. Note that for the ponded case, the melt pond did not form until mid-July.

In March the unponded ice was $2.25 \mathrm{~m}$ thick and had a $0.25 \mathrm{~m}$ snow cover. The snow cover increased to $0.45 \mathrm{~cm}$ depth in late May, when the melt season began. The ice thinned from the end of May through late August through both surface and bottom ablation, reaching a thickness of $1.5 \mathrm{~m}$ in September. The ponded ice (Fig. 4b) was only $1.5 \mathrm{~m}$ thick in March, but had a $0.5 \mathrm{~m}$ deep snow cover. Melt started in late May, with ponding beginning in mid-July. As melt progressed, the pond deepened to $0.4 \mathrm{~m}$. By mid-August the ice had thinned to $0.3 \mathrm{~m}$ and measurements were halted.

The ice physical description presented in Figure $4 a$ and $b$ was used to define the ice optical properties used in
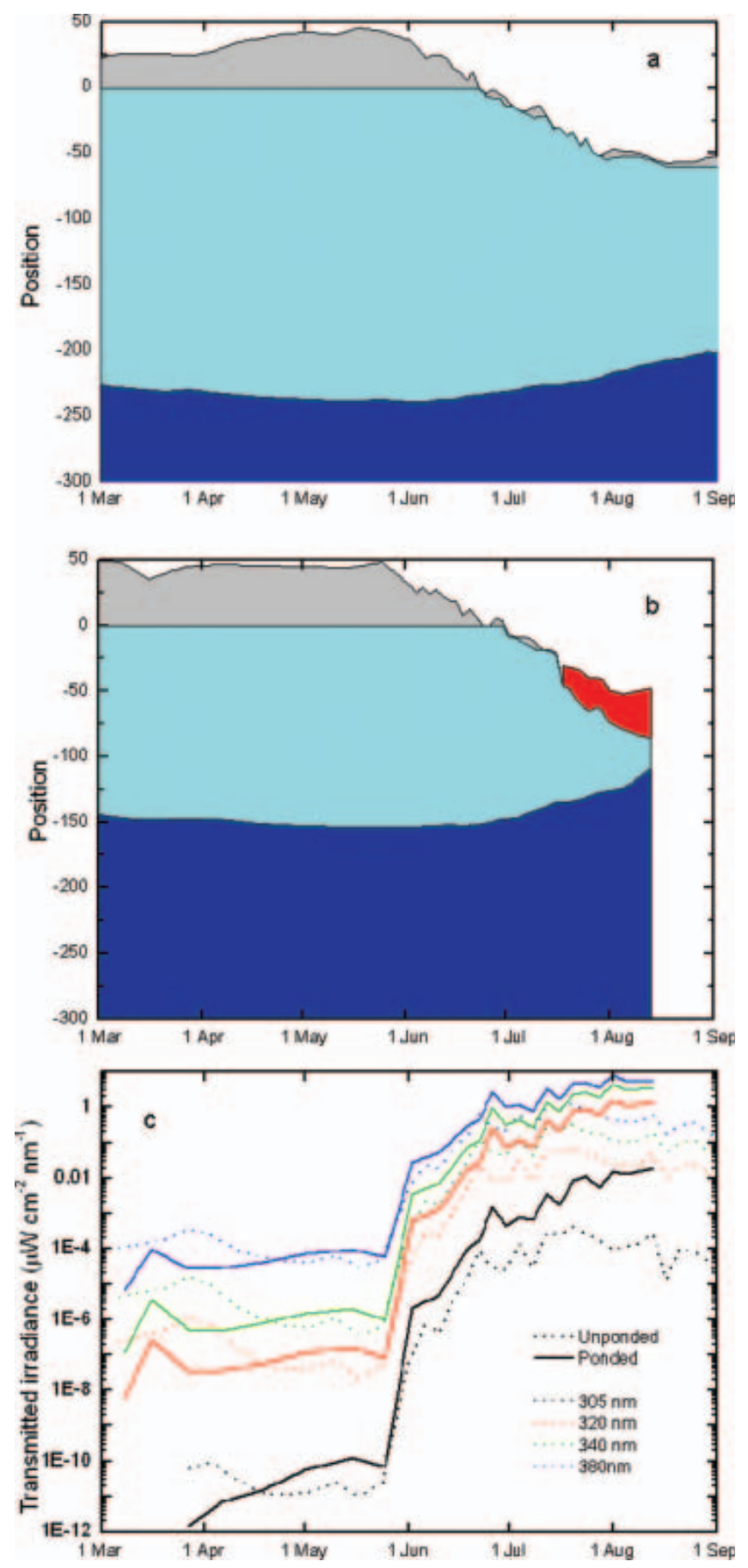

Fig. 4. Time series of (a) snow depth and ice thickness for unponded ice; (b) snow depth and ice thickness for ponded ice; and (c) calculated values of transmitted ultraviolet irradiance. Gray is snow, cyan is ice, and red is a melt pond.

radiative transfer modeling. Using this characterization and the observed incident ultraviolet irradiance, the model calculated the transmitted ultraviolet irradiance from March through September for ponded and unponded ice (Fig. 4c). The calculated transmitted irradiance exhibits the same general spectral dependence as the incident irradiances. From March until late May the calculated transmitted irradiance is quite small, $<10^{-4} \mu \mathrm{W} \mathrm{cm}^{-2} \mathrm{~nm}^{-1}$ at all wavelengths. During this period, differences between the two cases were largely driven by differences in snow depth: the deeper snow cover in March and April on the ponded ice resulted in less transmitted irradiance. The greatest 

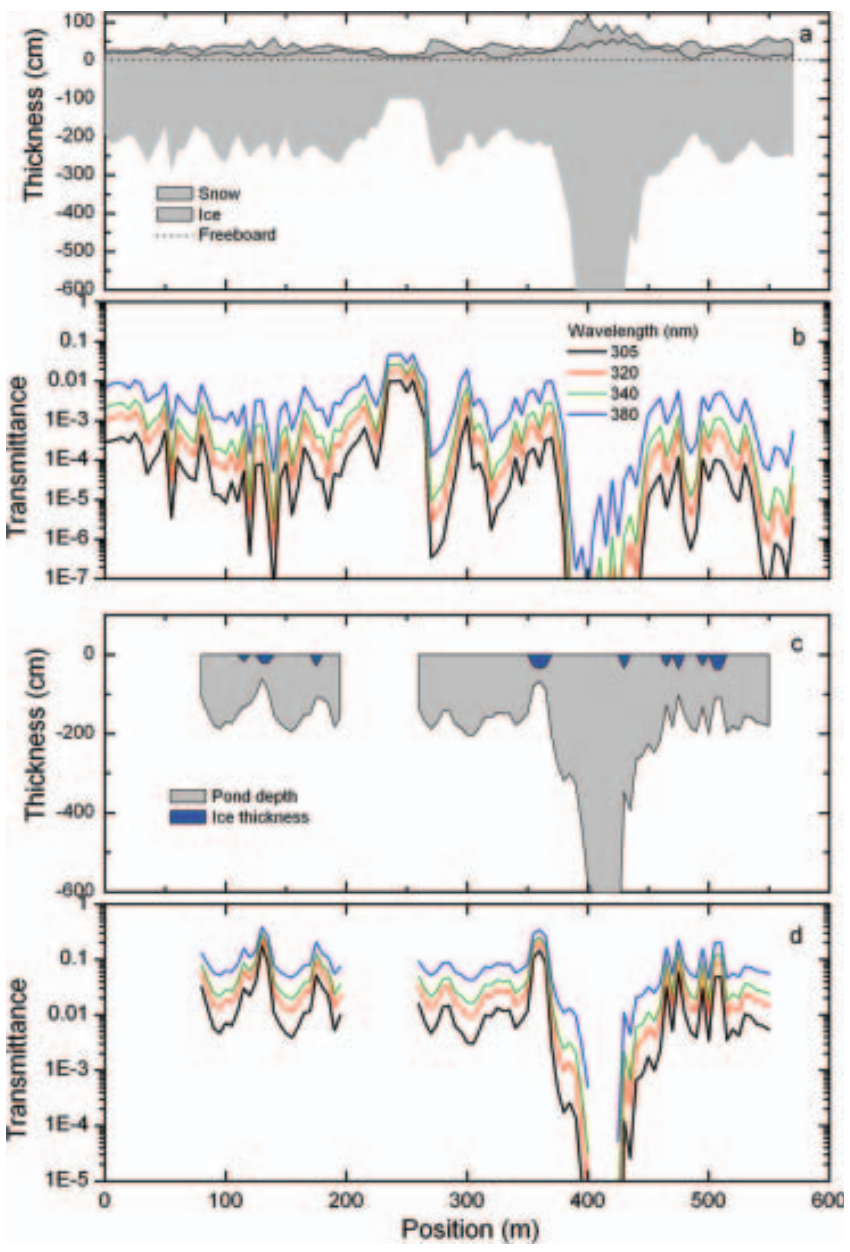

Fig. 5. Spatial variability of (a) snow depth and ice thickness on 10 June; (b) ultraviolet transmittance on 10 June; (c) snow depth and ice thickness on 3 August; and (d) ultraviolet transmittance on 3 August.

change in calculated ultraviolet transmitted irradiance occurred at the onset of melt in late May. During the span of only a few days, values increased by four orders of magnitude as the snow cover transformed from dry snow to thinner melting snow. This was followed by a fairly steady increase in transmitted irradiance throughout the rest of the summer melt season. Once the snow melts, the transmission through the thinner ponded ice is greater. The difference between the two cases becomes even more pronounced in mid-July once the melt pond forms. At this point, the surface scattering layer of the ice is gone and the albedo decreases, allowing more light to be transmitted. By 1 August the melt-pond transmission is 150 times greater at $305 \mathrm{~nm}, 56$ times greater at $320 \mathrm{~nm}, 32$ times greater at $340 \mathrm{~nm}$ and 16 times greater at $380 \mathrm{~nm}$ than the unponded case. The difference in transmission between the unponded and ponded cases was a direct consequence of the spectral dependence of the absorption coefficient of ice, which increases as wavelength decreases from $400 \mathrm{~nm}$ to $250 \mathrm{~nm}$ (Perovich and Govoni, 1991). Thus the calculations indicated that the transmitted irradiance at shorter wavelengths is more sensitive to the ice thickness. Even though the incident ultraviolet irradiance began to decline in midJune, the transmitted irradiance continues to increase until mid-August. This was due to the warming and thinning of the ice.

\section{Spatial variability of calculated transmittance ultraviolet irradiance}

The ponded and unponded cases illustrate the broad seasonal trends in transmitted ultraviolet irradiance. However, there is also considerable spatial variability in the physical properties of the sea-ice cover that can affect the ultraviolet transmittance. The impact of the spatial variability is greatest during the summer melt season, when the transmitted irradiance is impacted by differences in ice thickness, a patchy snow cover and the presence or absence of melt ponds.

The spatial variability of transmitted ultraviolet was explored using results from snow-depth and ice-thickness transects (Eicken and others, 2001). Observations were selected from transects made near the beginning of melt and peak incident (10 June) and at the height of the melt season (3 August). Figure 5a shows a $550 \mathrm{~m}$ long profile of snow depth and ice thickness measured on 10 June. The snow is melting and snow depths range from 0 to $80 \mathrm{~cm}$. Prominent features along the line included a section of $1 \mathrm{~m}$ thick firstyear ice, as well as an $8 \mathrm{~m}$ thick ridge.

Measured snow depths and ice thickness were used with the ultraviolet radiative transfer model to compute the transmittance along the line (Fig. 5b). Note that in this case we present the transmittance, the fraction of the incident ultraviolet irradiance, rather than the transmitted irradiance. The transmitted irradiance can be computed simply by multiplying the transmittance by the incident irradiance. As before, the calculated transmittance increases with wavelength due to the spectral dependence of the absorption coefficient of ice (Perovich and Govoni, 1991). Statistics of the calculated transmittance along the survey line are summarized in Table 1. The mean transmittance at $305 \mathrm{~nm}$ for the survey line was 0.0005 . Not surprisingly, the greatest transmittance was through the thin first-year ice and the smallest through the thick ridge. The maximum transmittance was 0.01 under the first-year ice, though everywhere else the transmittance was $<0.001$. Transmittances ranged over 12 orders of magnitude from the bare first-year ice to the heavily snow-drifted ridge.

Figure $5 \mathrm{c}$ shows the ice morphology along the same survey line on 3 August. The changes were dramatic: the first section of the line broke off, the first-year ice completely melted, the entire snow cover melted, there was substantial thinning of the ice, and several melt ponds formed. Ultraviolet transmittances for 3 August calculated using these physical properties are plotted in Figure $5 \mathrm{~d}$. There was a marked increase in transmittance calculated at all positions for all wavelengths. Ponded ice had the largest transmittance, typically a factor of 10-15 greater than bare ice. In essence, the melt ponds are skylights for ultraviolet light to reach the underside of the ice. At $305 \mathrm{~nm}$ the mean increased to 0.018 , the median to 0.0067 and the maximum to 0.18 . Most significantly, $86 \%$ of the survey line had $305 \mathrm{~nm}$ transmittances greater than 0.001 and $39 \%$ was greater than 0.01 . These large ultraviolet transmittances may have harmful impacts on biological activity at the underside of the ice.

\section{CONCLUSIONS}

The incident ultraviolet irradiance exhibited a strong seasonal dependence, with a peak on 14 June, 1 week before the summer solstice. This dependence was primarily a result 
Table 1. Statistics of ultraviolet light transmittance on 10 June and 3 August 1998

\begin{tabular}{|c|c|c|c|c|c|c|c|c|}
\hline & \multicolumn{2}{|c|}{$305 \mathrm{~nm}$} & \multicolumn{2}{|c|}{$320 \mathrm{~nm}$} & \multicolumn{2}{|c|}{$340 \mathrm{~nm}$} & \multicolumn{2}{|c|}{$380 \mathrm{~nm}$} \\
\hline & 10 June & 3 August & 10 June & 3 August & 10 June & 3 August & 10 June & 3 August \\
\hline Mean & $5.2 \times 10^{-4}$ & $1.8 \times 10^{-2}$ & $1.2 \times 10^{-3}$ & $3.4 \times 10^{-2}$ & $2.0 \times 10^{-3}$ & $4.7 \times 10^{-2}$ & $5.1 \times 10^{-3}$ & $8.5 \times 10^{-2}$ \\
\hline Median & $3.4 \times 10^{-5}$ & $6.7 \times 10^{-3}$ & $1.7 \times 10^{-4}$ & $1.7 \times 10^{-2}$ & $4.0 \times 10^{-4}$ & $2.8 \times 10^{-2}$ & $2.0 \times 10^{-3}$ & $6.2 \times 10^{-2}$ \\
\hline Minimum & $6.9 \times 10^{-4}$ & $2.4 \times 10^{-9}$ & $9.8 \times 10^{-12}$ & $1.6 \times 10^{-7}$ & $1.4 \times 10^{-10}$ & $1.3 \times 10^{-6}$ & $4.3 \times 10^{-8}$ & $5.2 \times 10^{-5}$ \\
\hline Maximum & $1.0 \times 10^{-2}$ & $1.8 \times 10^{-1}$ & $1.9 \times 10^{-2}$ & $2.5 \times 10^{-1}$ & $2.7 \times 10^{-2}$ & $2.9 \times 10^{-1}$ & $4.7 \times 10^{-2}$ & $3.8 \times 10^{-1}$ \\
\hline
\end{tabular}

of changes in solar zenith angle, with a secondary contribution from increasing cloudiness during summer. Day-today fluctuations in ultraviolet incident of a factor of two were common and resulted from changing cloud conditions. Observations of incident ultraviolet irradiance and calculated values of transmitted ultraviolet irradiance all increase at longer wavelengths.

The ice was covered by melting snow in mid-June, when the incident ultraviolet irradiance was greatest. The transmitted ultraviolet irradiance increased throughout the summer melt season as the snow melted, the ice thinned and ponds formed, finally reaching maximum values in midAugust. Melt ponds have a large impact on transmittance, typically increasing the amount of ultraviolet light reaching the underside of the ice and the upper ocean by an order of magnitude.

Changes in the seasonal evolution of sea-ice morphology could have significant impacts on the interaction of ultraviolet light with the ice cover. For example, the current warming of the Arctic is altering the amplitude and timing of the annual albedo cycle of sea ice. Melt seasons are beginning earlier and the annual decrease in albedo is greater. With this decrease in albedo there will be an increase in transmittance. Compounding the impact, an earlier melt onset will increase transmittance during the period when the incident ultraviolet irradiance is greatest. Such a significant enhancement of ultraviolet transmittance has the potential for deleterious biological impacts.

\section{ACKNOWLEDGEMENTS}

We thank J. Richter-Menge for helpful discussions regarding the manuscript, and J. Govoni and B. Elder for assistance with the field observations. This work has been supported by the Arctic System Science program of the US National Science Foundation.

\section{REFERENCES}

Booth, C.R., J.H. Morrow and J.P. Schmidt. 1995. UV-B irradiance monitoring network design and demonstration. Final report for NOAA Phase I Contract DKNA-4-00090: strategy for a UV-B monitoring network: instrument selection, calibration and data products. San Diego, CA, Biospherical Instruments Inc.

Cota, G.F., J.L. Anning, L.R. Harris, W.G. Harrison and R.E.H. Smith. 1990. Impact of ice algae on inorganic nutrients in seawater and sea ice in Barrow Strait, N.W.T., Canada, during spring. Can. J. Fish. Aquat. Sci., 47(7), 1402-1415.

Cota, G.F., L. Legendre, M. Gosselin and R.G. Ingram. 1991. Ecology of bottom ice algae: I. Environmental controls and variability. J. Mar. Syst., 2(3-4), 257-277.
Eicken, H., W.B. Tucker, III and D.K. Perovich. 2001. Indirect measurements of the mass balance of summer Arctic sea ice with an electromagnetic induction technique. Ann. Glaciol., 33, 194-200.

Gosselin, M., M. Levasseur, P.A. Wheeler, R.A. Horner and B.C. Booth. 1997. New measurements of phytoplankton and ice algal production in the Arctic Ocean. Deep-Sea Res. II, 44(8), 1623-1625.

Grenfell, T.C. 1983. A theoretical model of the optical properties of sea ice in the visible and near infrared. J. Geophys. Res., 88(C14), 9723-9735.

Grenfell, T.C. 1991. A radiative transfer model for sea ice with vertical structure variations. J. Geophys. Res., 96(C9), 16,991$17,001$.

Grenfell, T.C. and G.A. Maykut. 1977. The optical properties of ice and snow in the Arctic Basin. J. Glaciol., 18(80), 445-463.

Helbling, E.W., V. Villafañe and O. Holm-Hansen. 1994. Effects of ultraviolet radiation on Antarctic marine phytoplankton photosynthesis with particular attention to the influence of mixing. In Weiler, C.S. and P.A. Penhale, eds. Ultraviolet radiation and biological research in Antarctica. Washington, DC, American Geophysical Union, 207-227. (Antarctic Research Series 62.)

Horner, R. and 9 others. 1992. Ecology of sea ice biota. 1. Habitat, terminology, and methodology. Polar Biol., 12(3-4), 417-427.

Karentz, D. 1994. Ultraviolet tolerance mechanisms in Antarctic marine organisms. In Weiler, C.S. and P.A. Penhale, eds. Ultraviolet radiation in Antarctica: measurements and biological effects. Washington, DC, American Geophysical Union, 93110. (Antarctic Research Series 62.)

Light, B., G.A. Maykut and T.C. Grenfell. 2003a. Effects of temperature on the microstructure of first-year Arctic sea ice. J. Geophys. Res., 108(C2), 3051. (10.1029/2001JC000887.)

Light, B., G.A. Maykut and T.C. Grenfell. 2003b. A twodimensional Monte Carlo model of radiative transfer in sea ice. J. Geophys. Res., 108(C7), 3219. (10.1029/2002JC001513.)

McMinn, A., C. Ashworth and K. Ryan. 1999. Growth and productivity of Antarctic sea ice algae under PAR and UV irradiances. Bot. Mar., 42(4), 401-407.

Palmisano, A.C. and C.W. Sullivan. 1983. Sea ice microbial communities. 1. Distribution, abundance, and primary production of ice microalgae in McMurdo Sound, Antarctica in 1980. Polar Biol., 2(3), 171-177.

Perovich, D.K. 1990. Theoretical estimates of light reflection and transmission by spatially complex and temporally varying sea ice covers. J. Geophys. Res., 95(C6), 9557-9567.

Perovich, D.K. 1993. A theoretical model of ultraviolet light transmission through Antarctic sea ice. J. Geophys. Res., 98(C12), 22,579-22,587.

Perovich, D.K. 2001. UV radiation and the optical properties of sea ice and snow. In Hessen, D., ed. UV radiation and Arctic ecosystems. Berlin, Springer Verlag, 73-89.

Perovich, D.K. and J.W. Govoni. 1991. Absorption coefficients of ice from 250 to $400 \mathrm{~nm}$. Geophys. Res. Lett., 18(7), 1233-1235.

Perovich, D.K. and 22 others. 1999. Year on ice gives climate insights. EOS Trans. AGU, 80(41), 481, 485-486. 
Perovich, D.K., T.C. Grenfell, B. Light and P.V. Hobbs. 2002. Seasonal evolution of the albedo of multiyear Arctic sea ice. J. Geophys. Res., 107(C10), 8044. (10.1029/2000JC000438.)

Perovich, D.K., T.C. Grenfell, J.A. Richter-Menge, B. Light, W.B. Tucker, III and H. Eicken. 2003. Thin and thinner: ice mass balance measurements during SHEBA. J. Geophys. Res., 108(C3), 8050. (10.1029/2001JC001079.)

Prézelin, B.B., N.P. Boucher and R.C. Smith. 1994. Icecolors '90: marine primary production under the influence of the Antarctic ozone hole. In Weiler, C.S. and P.A. Penhale, eds. Ultraviolet radiation in Antarctica: measurements and biological effects. Washington, DC, American Geophysical Union, 159-186. (Antarctic Research Series 62.)

Prézelin, B.B., M.A. Moline and H.A. Matlick. 1998. Icecolors '93: spectral UV radiation effects on Antarctic frazil ice algae. In
Lizotte, M.P. and K.R. Arrigo, eds. Antarctic sea ice: biological processes, interactions and variability. Washington, DC, American Geophysical Union, 45-83. (Antarctic Research Series 73.)

Smith, R.C. and 12 others. 1992. Ozone depletion: ultraviolet radiation and phytoplankton biology in Antarctic waters. Science, 255(5047), 952-959.

Thomas, D.N. and G.S. Dieckmann. 2002. Biogeochemistry of Antarctic sea ice. In Gibson, R.N., M. Barnes and R.J.A. Atkinson, eds. Oceanography and marine biology: an annual review. Vol. 40. London, Taylor and Francis, 143-169.

Trodahl, H.J. and R.G. Buckley. 1990. Enhanced ultraviolet levels under sea ice during the austral spring. Geophys. Res. Lett., 17(12), 2177-2179.

Uttal, T. and 27 others. 2002. Surface heat budget of the Arctic Ocean. Bull. Am. Meteorol. Soc., 83(2), 255-275. 